\title{
PASTURE ESTABLISHMENT BY SURFACE SOWING IN THE TE ANAU DISTRICT
}

\author{
D. R. Marshall
}

\author{
Lands and Survey Department, Te Arzau
}

\section{Summary}

Establishing pasture on ploughable land in the Te Anau district by surface sowing has been successful and this method proved less costly than conventional cultivation techniques. Clover must be inoculated, preferably coated and sown as soon as possible after inoculation. It is desirable to coat the grass seed, particularly if application is to be made from the air. At least $1,255 \mathrm{~kg} /$ ha of superphosphate are recommended in the first twelve months, plus molybdenum. The herbage of the unimproved land should be adequate to protect the seedlings, yet not too dense to stop the pelleted seed making contact with the soil. Burning is undesirable. An even distribution of seed is essential. These areas will carry 9.5 stock units/ ha in the fourth year.

\section{INTRODUCTION}

The DeVELopment of land in Te Anau to provide economic farms for the community was started by the Government through its agency, the Lands and Survey Department, in 1953, with the purchase of Lynwood station of 25,597 ha. Further purchases over the following seven years, together with unalienated Crown land, brought the total up to 49,778 ha. This is expected to produce 200 sheep farms of which 34 have been settled, involving 6,270 ha.

The Department is currently farming in this district 22,258 ha of sown pasture and a further 12,140 ha are suitable for development. Livestock numbers have increased from 5,000 sheep and 1,600 beef cattle to 180,000 sheep and 10,000 beef cattle as at June 1972.

Initially pasture was established by cultivating to a seedbed the natural herbage, consisting of fern, scrub and tussock. The limited results achieved encouraged the Department of Agriculture to carry out extensive pasture establishment trials from which came the guide-lines for future pasture establishment. These in principal were clover inoculation and adequate quantities of superphosphate. Successful pasture establishment followed, but costs were high and difficulties in recovering these costs were foreseen. The new technique of pasture establishment by surface 
sowing then followed. This is a means of introducing pasture seed into unimproved land without first having mechanically cultivated the soil. Over the last six years, 7,285 ha of pasture have been successfully established using this method. There is no argument, when one is considering establishing pasture on unploughable country, that surface sowing from the air is the only practical method. In this paper, however, it is intended to show that pasture can be successfully established on easy contoured, ploughable land from the unimproved state by surface sowing, achieving the same end result but with considerable other advantages.

Successful pasture establishment by surface sowing is considered the most significant single factor over recent years in making the development to grassland of unimproved, low fertility country an economic proposition. By this is meant that the margin between the costs of development and the capital value of the improved land are closer under this method than under methods used in the past. This is a very significant factor, because all costs are expected to be recovered on settlement.

\section{CLIMATE AND SOILS}

Climatic conditions in the Te Anau district are favoureble for successful pasture establishment by surface sowing. Altitudes range from 213 to $610 \mathrm{~m}$ above sea level and the rainfall averages $1,200 \mathrm{~mm} /$ annum, generally being well distributed, although dry springs can occur. Mean temperatures range from 3" $\mathrm{C}$ in July to 14" C in February.

Soils are of three main types, Te Anau and Monowai, formed on morainic deposits with stony to very stony and bouldery profiles, and Lynwood, which has been formed from greywacke, volanic and metamorphic rocks with a thin covering of loess (N.Z. Soil Bureau, 1968).

The original cover consisted of red and fescue tussock, fern, scrub, matagouri and beech forest.

Soil analysis determined by the Department of Agriculture indicated the following levels on undeveloped soil: $\mathrm{pH}$ 5.2-5.3; Ca $1 ; \mathrm{K} \mathrm{2;} \mathrm{P} \mathrm{2-5*.}$

${ }^{*} \mathrm{Ca}=$ parts per 40,000 of neutral normal ammonium acetatae extractrant. $\mathrm{K}=$ parts per 25,000 of neutral normal ammonium acetate ex. tractant. $\mathrm{P}=$ parts per 50 million of Truog reagent, 
This represents a very low nutrient status. Good responses are obtained with the use of superphosphate, but lime is not essential for initial clover establishment where molybdenum is used.

\section{THE TECHNIQUES OF SURFACE SOWING}

The main types of cover - i.e., tussock, scrub, fern and high manuka - must be treated in different ways prior to surface sowing. Burning is undesirable, except with high manuka, because it over-exposes the soil to frosts and cold winds. Also, the tutu present in this fern country increases greatly and later creates grazing problems. Tussock needs little or no treatment before surface sowing. The natural cover here is ideal for young seedlings to establish and it is important that adequate top cover is retained. Fern and low scrub should be slashed with a rotary mower where contour and absence of boulders permit. Alternatively, it may be fenced and crushed with cattle, preferably during the previous autumn and winter, and the use of hay at this time will assist.

Good results are obtained by sowing pelleted seed in August when temperatures are rising and soil conditions moist. The ap plication of seed either can be done from the air or by using ground machinery. An even distribution is most important and in aerial application this is aided by applying the pelleted seed in two applications' at about half the total weight each time, not necessarily in different directions. Flying at $24 \mathrm{~m}$ above the ground at $177 \mathrm{~km} / \mathrm{hr}$ gives good control of seed spread with maximum ballistic effect.

Commercially inoculated and pelleted clover seed and commercially phosphate-coated grass seed are used. High quality varieties of grass and clover seed are recommended. It is important that the clovers are properly inoculated with the best strains of rhizobia and sown as soon as possible after inoculation. Storing the seed should be avoided, particularly under conditions of high temperatures.

For the purposes of surface sowing, by aerial application there is a definite advantage from coating the grass seed apart from any benefit gained from the phosphate as a fertilizer. This is the ballistic effect produced by the heavier pellet falling at speed, penetrating the top cover, and making direct contact with the soil. 


\section{SEed MTXTURE}

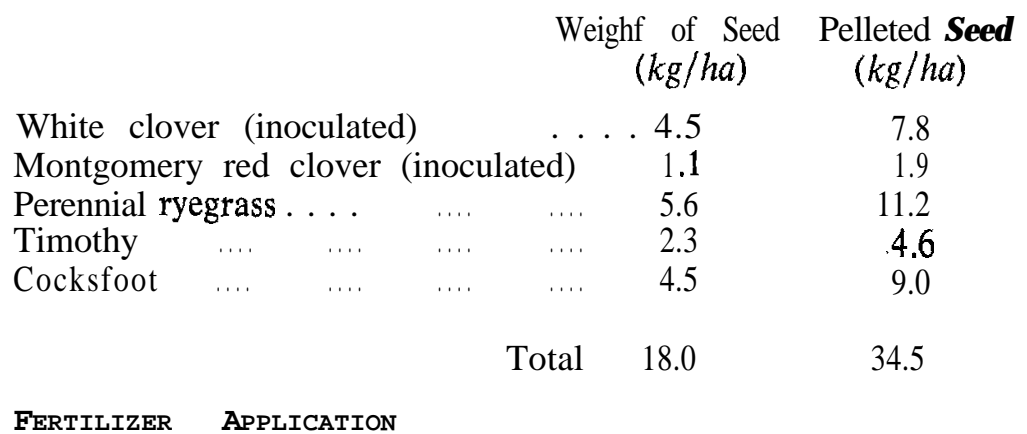

During the first twelve months, $1,255 \mathrm{~kg}$ of superphosphate per hectare is applied in three applications, with the initial $500 \mathrm{~kg}$ being sown 4 to 6 weeks prior to the seed being applied. Maintenance applications consist of $377 \mathrm{~kg} / \mathrm{ha}$ of superphosphate annually. Only superphosphate has been used, except for one instance where an application of potassic superphosphate was tried with no visible response. Molybdenum is applied once with the fertilizer and lime has not been applied at any stage.

\section{Costs of Surface Sowing}

Pelleted seed plus mixing and freight

$1,255 \mathrm{~kg}$ of superphosphate plus freight 100 miles, less subsidies

$\$ 19.42$ Aerial application of pelleted seed $\ldots \ldots \ldots$

Total establishment cost $\$ 45.90$

These prices are based on sowing 400 ha and the total subsidy involved is $\$ 19.64 / \mathrm{ha}$. A further $\$ 5.73$ is required if potassic superphosphate $(33 \%)$ is used, plus $\$ 12.35 /$ ha for rotary slashing if this is necessary. Compared with development through cultivation, there is a saving of $\$ 32$ to $\$ 44 /$ ha for a similar end result.

\section{CARRYING CAPACITIES AND MANAGEMENT}

The initial strike of clover within a month of sowing is outstanding, but mortality of the seedling clovers is high at the two- 
leaf stage. On-and-off grazing, using sheep, commences about November and gradually intensifies, using the same pattern together with cattle. Ryegrass and cocksfoot do not appear in the sward to any extent until the third year. Where tussock was present initially, it remains quite dominant and in some instances, on shady faces, could be increasing, At this stage, however, it is not considered a problem.

-Carrying capacities of surface-sown areas 12 months after sowing reach 5 stock units*/ha and these increase to 9.5 stock units/ ha in the fourth year. Ultimate carrying capacities are pure conjecture in this district because the techniques employed have been used over only a comparatively short period, but it is felt that they will be as good as the results achieved by cultivation.

\section{ADVANTAGES OF SURFACE SOWING}

(1) Less capital is involved for the same result, therefore charges on capital invested are more easily recovered.

(2) Consolidation of the soil is unaffected bringing two advantages:

(a) There is less drying out under drought conditions.

(b) The problem of rush infestation associated with earlier pasture establishment, particularly on the Lynwood soil type, does not seem to occur.

\section{DISADVANTAGES OF SURFACE SOWING}

(1) Using incorrect or only some of the techniques mentioned can produce very poor results.

(2) Paddocks are left with a rough, unlevelled surface.

(3) Grasses generally are slow to establish.

\section{CONCLUSION}

Pasture establishment by the surface sowing method, using the techniques discussed, should be considered in any area receiving a rainfall of more than $600 \mathrm{~mm}$ annually. The methods employed are effective and are producing, good results in Te Anau. There

*Stock unit equivalents: 1 breeding ewe $=1 ; 1$ hogget $=0.6 ; 1$ dry adult sheep $=0.8 ; 1$ breeding cow $=6$; other cattle $=4$. 
is room, however, for further improvement, and this could centre around:

(1) Investigating the reasons for the high mortality rate in seedlings up to one month after germination.

(2) Devising ways of being able to establish grasses at an earlier date in the clover-dominant sward.

(3) Examining the ballistic effect of the pellet to ascertain whether a larger pellet would produce better results.

(4) Examining the possibility of combining the fertilizer with the seed to reduce costs further.

(5) Examining the possibility of applying 1,255 kg/ha of superphosphate in one instead of three applications.

\section{REFERENCE}

N.Z. Soil Bureau, 1968. N.Z. Soil B ur. Bull. 27, 404 pp. 